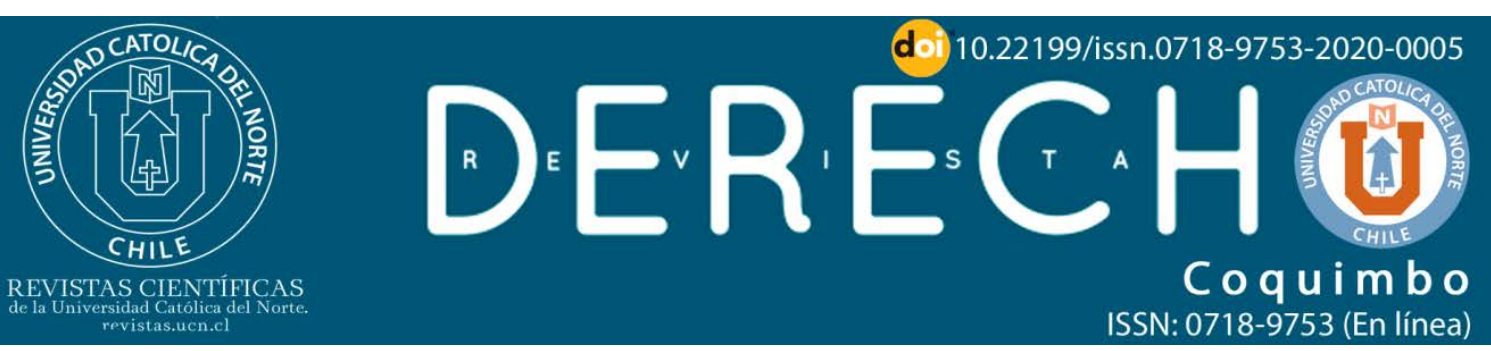

\title{
La incidencia del Covid-19 en el ejercicio de la garantía legal
}

\section{The incidence of the Covid-19 in the legal guarantee}

\section{Erika Isler Soto' 1 Dhttps://orcid.org/0000-0002-2545-9331}

${ }^{1}$ Universidad de Talca, Talca, Chile. Profesora de Derecho Civil. Doctora en Derecho, P. U. Católica de Chile.

(هisler@utalca.cl

(cc) BY

\section{Resumen:}

Se aborda la incidencia de la aparición del virus Covid-19 en los derechos derivados de la garantía legal, en la legislación chilena. Se postula en primer lugar que esta pandemia efectivamente puede ser considerada como un caso fortuito, pero no extingue el deber de garantía. No obstante, se producen dos efectos: la suspensión del plazo legal para su ejercicio y el surgimiento de ciertos deberes de conducta. Dicho planteamiento se obtiene de la necesidad de resguardar la seguridad de los consumidores, así como de los principios y reglas que disciplinan los plazos extintivos, con una especial referencia al Derecho de Consumo.

Palabras Clave: Consumidores; Prescripción; Pandemia; COVID-19; Coronavirus.

\begin{abstract}
:
The incidence of the COVID-19 virus in the rights derived from the legal guarantee, in Chilean Consumer Law. At first, it is postulated that this pandemic can indeed be considered as a force majeure, but it does not extinguish the guarantee. However, there are two effects: the suspension of the legal term for its exercise and the emergence of certain duties of conduct. This approach is obtained from the need to safeguard the safety of consumers, as well as from the principles and rules of the statute of limitations, with special reference to Consumer Law.

Keywords: Consumers; Statute of limitations; Pandemic; COVID-19.
\end{abstract}




\section{Introducción}

La Ley 19.496 sobre Protección de los Derechos de los Consumidores, confiere al consumidor que ha sido defraudado en la adquisición de un producto el derecho a optar entre su cambio, reparación o la devolución del precio que hubiere pagado por él (Ley $N^{\circ} 19.496,2019$, art. 20, inc. 1).

Por otra parte, si bien Chile se ha caracterizado por la ocurrencia de desastres naturales, la aparición del COVID-19 en el escenario mundial dio origen a una emergencia, cuyas consecuencias se alejaban de las frecuentes catástrofes nacionales; sobre esta temática en el ámbito nacional, destaca el trabajo de San Martín Neira (2019, pp. 123-142). Tal escenario ha desafiado también al Derecho, obligando a legisladores y juristas a preguntarse acerca de la aplicación y adecuación de instituciones y reglas abstractas ya reconocidas, a un escenario en el cual las generaciones actuales no pensaron que iban a transitar. Así, el caso fortuito, la fuerza mayor, la imprevisión, el (in)cumplimiento y la imposibilidad en la satisfacción son algunos ejemplos de temáticas que han emergido desde el Derecho Común, para ser abordadas a la luz de una emergencia mundial y cuya superación tiene todavía mayores o menores incertezas. La aparición y desarrollo de la emergencia del COVID-19, ha motivado diversos análisis de las consecuencias jurídicas a que pudiere dar lugar. Al tratarse de hechos recientes, han sido tratados en general en columnas de opinión y no en artículos científicos ${ }^{1}$.

La masividad de la configuración de relaciones de consumo en tanto, ha reclamado una vez más la necesidad de una regulación suficiente, integral y clara que las aborde, desde que la gran mayoría de los afectados por la contingencia pueden ser calificados de consumidores o bien de empresas susceptibles de invocar la misma normativa.

En este contexto, tanto las medidas imperativas adoptadas por la autoridad (cuarentenas, confinamiento, cordones y aduanas sanitarias, prohibición de funcionamiento de ciertos establecimientos), como las recomendaciones de los expertos y del mismo gobierno (distancia física e higiene), ha generado la paralización de las actividades económicas, además de la imposibilidad de ejercer ciertos derechos conferidos por el sistema nacional de consumo al consumidor defraudado, entre los cuales se encuentra la garantía legal.

La duda que emerge entonces, dice relación con las eventuales consecuencias jurídicas que el COVID-19 en concreto produce respecto de este remedio, esto es si fenece por su ocurrencia, o si por el contrario, persiste bajo ciertas condiciones y

\footnotetext{
1 Por ejemplo: De la Maza Gazmuri (2020); De la Maza Gazmuri y Vidal Olivares (2020); Pizarro Wilson (2020b); San Martín Neira (2020). Sobre los deberes del arrendatario frente al COVID-19, Momberg Uribe (2020). Sobre el pago de remuneraciones: Corral Talciani (2020). Sobre la prescripción extintiva: Corral Talciani (2020b); Pizarro Wilson (2020).
} 
términos. Pensemos en el caso de aquel individuo que adquirió un producto, y no obstante evidenciar una falla funcional dentro del término indicado, no puede concurrir físicamente a los establecimientos del vendedor a realizar la reclamación correspondiente. ¿El plazo que tiene para ello continúa corriendo, o bien es posible defender su suspensión hasta que la emergencia se haya controlado? ¿Surgen nuevos deberes o se extinguen irrevocablemente los ya existentes?

La Ley 19.496 sobre Protección de los Derechos de los Consumidores no resuelve la interrogante planteada, ni tampoco explicita reglas referentes a la procedencia y efectos del caso fortuito o fuerza mayor en esta materia. El propósito de este trabajo entonces, consiste en proponer una respuesta a tal disyuntiva a partir de las normas y principios que sí se contemplan en el sistema nacional de consumo. Para lograr lo anterior, el texto comienza con el análisis de la calificación jurídica de la pandemia actual, para luego abordarse su incidencia en la garantía legal.

\section{COVID-19 y caso fortuito}

Para abordar adecuadamente la pregunta que motivó este texto, se debe distinguir entre la calificación de la pandemia como caso fortuito y los posibles efectos jurídicos a que ello pudiere dar lugar. Resulta útil en este punto, la distinción entre la ocurrencia y la perniciosidad del caso fortuito (San Martín Neira, 2020).

\section{1. ¿Constituye la pandemia del COVID-19 un supuesto de caso fortuito?}

De acuerdo al Código Civil, se entiende por caso fortuito o fuerza mayor al "...imprevisto a que no es posible resistir, como un naufragio, un terremoto, el apresamiento de enemigos, los actos de autoridad ejercidos por un funcionario público, etc." (Código Civil, 2000, art 45). Los presupuestos de configuración serían entonces la irresistibilidad, la imprevisibilidad y la exterioridad (Brantt Zumarán, 2011, p. 49; Brantt Zumarán, 2009, p. 40).

Pizarro Wilson por su parte, ha señalado que la imprevisibilidad y la irresistibilidad deben ponderarse en conexión con el contrato de que se trate, al momento de su celebración: "...la diligencia para prever y para resistir el hecho que se pretende fuerza mayor, debe efectuarse considerando el contrato, su contenido, las negociaciones y el propósito del acuerdo" (Pizarro Wilson, 2020b). A consecuencia de lo anterior, se presentará el caso fortuito en la medida de que un evento escape al control de un deudor que no podía representárselo al momento en que el contrato nació a la vida del derecho (Pizarro Wilson, 2020b).

Con todo, examinados los requisitos a la luz de la pandemia actual, en general existe un consenso (De la Maza Gazmuri y Vidal Olivares, 2020; Pizarro Wilson, 2020b; en Argentina, Arias, 2020) - que comparto- en orden a considerar que efectivamente 
se cumplen, y por lo tanto puede ser calificada de caso fortuito. En efecto, la aparición del virus, pero sobre todo de su altísima aptitud de contagio, escapó a las predicciones que un acreedor o un deudor pudo representarse con anterioridad a que saliera a la luz pública. Lo anterior se evidencia en la sorpresa que no sólo generó en particulares, sino que incluso en Estados que se han visto sobrepasados por la emergencia. Y si bien hoy en día han surgido algunas voces que han acusado una reacción tardía por parte de los gobiernos de algunos países, lo cierto es que la magnitud de la catástrofe recién fue dimensionada con bastante posterioridad a su inicio.

No obsta lo anterior, el carácter mixto de las pandemias al que alude San Martín Neira (2020) -origen natural y expansión antrópica- en el sentido de que el control de los efectos del COVID-19, conocidamente constituye un difícil desafío para la humanidad entera.

¿Significa lo anterior, que extinga automáticamente las obligaciones pendientes? Responde Pizarro Wilson:

El Covid-19 es un caso fortuito en cuanto a su ocurrencia [...] pero lo más relevante es si las consecuencias del mismo en los contratos pueden resistirse considerando la diligencia exigible al deudor. Es la importante diferencia entre el hecho mismo y los efectos del Covid-19. La diligencia para mensurar las condiciones y los efectos de la fuerza mayor da la necesaria flexibilidad a esta institución en el derecho de los contratos. (Pizarro Wilson, 2020b)

A continuación, entonces, se examinará este segundo estadio de la cuestión.

\subsection{Los efectos de la ocurrencia de la pandemia}

Lo que cabe dilucidar ahora, es si la sola aparición del Sars Cov-2 y su concepción como un supuesto de caso fortuito, produce el efecto de hacer fenecer los derechos de los consumidores y en particular de la triple opción derivada de la garantía legal (cambio o reparación del producto, o devolución del precio). En concreto, debemos preguntarnos si los escasos 3 meses contados desde la entrega del producto (Ley $\mathrm{N}^{\circ}$ 19.496, 2019, art. 2, inc. 1) para el ejercicio del derecho, sigue corriendo mientras dura la emergencia, o bien si se puede considerar que su curso puede verse suspendido o interrumpido en favor del consumidor. Como se dijo, ello no es resuelto por la Ley 19.496. La Ley $N^{\circ} 21.226$ (2020) por su parte, si bien alude a algunos plazos, ninguno de ellos se refiere al del remedio aludido.

Brantt Zumarán (2011, p. 70), rechaza la extinción de la obligación por imposibilidad en el cumplimiento como supuesto unitario y único del caso fortuito - De la Maza Gazmuri (2020) señala que: "el caso fortuito siempre procede, sin embargo, de allí no se sigue que siempre opere de la misma forma"-, por cuanto ello implicaría confundir dos instituciones diferentes -caso fortuito e imposibilidad sobrevenida de la prestación- y sus correspondientes ámbitos: exoneración de responsabilidad (indemniza- 
ción) y la liberación de la obligación (Brantt Zumarán, 2011, p. 71). El caso fortuito por lo tanto, no bastaría para producir el efecto de extinguir una obligación, sin perjuicio de que podría constituir un elemento de la imposibilidad sobrevenida (Brantt Zumarán, 2011, p. 74). Carecería por lo tanto por sí solo, de eficacia extintiva (Brantt Zumarán, 2011, p. 74).

Para responder entonces a la interrogante inicial, se debe distinguir según si el caso fortuito -la pandemia- impide permanentemente la ejecución de la obligación o bien si la imposibilidad será sólo temporal, - a propósito del incumplimiento, en ausencia de disposición contractual, debe atenderse a tres distinciones: "La primera es si se trata de una obligación de dar una especie o cuerpo cierto. La segunda, [...] según si sus efectos son temporales o permanentes. La tercera, relativa a la situación del deudor y el acreedor..." (De la Maza Gazmuri y Vidal Olivares, 2020) -. En otras palabras, lo que debemos indagar es si el derecho que no puede ejercerse -la triple opción- podrá o no tener lugar, transcurrida la emergencia.

Si atendemos a la forma como hemos visto que se ha desarrollado la pandemia, es factible formarnos la esperanza de que su perniciosidad pueda detenerse o al menos disminuir en el tiempo. Las noticias que se difunden acerca de la fabricación de una vacuna que pueda hacerle frente, así como las expectativas que trasuntan detrás de la adopción de medidas adecuadas de contención y prevención, darían luces de que más temprano o más tarde, los establecimientos comerciales volverán a funcionar con una cierta -aunque nueva- normalidad. También en Argentina, se ha planteado que el COVID-19 genera una imposibilidad temporal para el ejercicio de los derechos de los consumidores (Arias, 2020). Ello permite sostener que la triple opción por lo tanto no debería fenecer, sino que ha de continuar vigente, sin perjuicio de que su ejercicio merecerá algunos comentarios adicionales. Se volverá sobre esto más adelante.

Así, en Argentina también ha señalado Arias, a propósito de la resolución (Ley 26.994, 2014, art. 1090),

...este acontecimiento anormal, sobreviniente y ajeno a la voluntad de las partes que es la enfermedad de COVID-19 con caracteres pandémicos tendrá una duración en el tiempo y, por ende, en general resultará aplicable la frustración temporaria del fin del contrato salvo que el cumplimiento oportuno de la obligación sea esencial... (Arias, 2020)

En nuestro país, la triple opción da lugar a la resolución del contrato, cuando se opta por la devolución del precio, previa restitución del bien (Barrientos Camus, 2014, p. 62).

A la misma conclusión arribamos, si consideramos que la triple opción tiene un carácter contractual (Brantt Zumarán, 2009, p. 93; Corral Talciani, 2011, p. 115) - no 
obstante, se la calificado también de postcontractual, y con ello discutido el régimen jurídico que le resulta aplicable (Benítez, 2013; Isler Soto, 2019, pp. 335-382)- y de responsabilidad objetiva ${ }^{2}$. Con todo, lo que se ha discutido en mayor medida, es la calificación de la acción indemnizatoria enunciada en la Ley $\mathrm{N}^{\circ}$ 19.496, 2019, art. 20 inc. 1 (Corral Talciani, 2011, p. 119), pudiéndose el proveedor liberar de ella, únicamente en caso de que el producto se hubiese deteriorado por un hecho imputable al deudor (Ley N 19.496, 2019, art. 21 inc. 1). Por tal razón, explica Corral Talciani (1999, p. 180), que su carácter imperativo (Ley $\mathrm{N}^{\circ} 19.496,2019$, arts. 19 y 20) conlleva a que no resulte admisible la alegación de ausencia de culpa o concurrencia de caso fortuito, como causales de exoneración de responsabilidad.

Con todo, la imposibilidad temporal ya aludida, si bien no extingue la obligación, puede dar lugar a dos consecuencias jurídicas importantes: la suspensión de la ejecución de ciertos deberes y obligaciones (Arias, 2020; Brantt Zumarán, 2011, p. 76; Pizarro Wilson, 2020b) (y con ello de los plazos extintivos a los cuales se encuentran sometidos) y el surgimiento de nuevos imperativos. Ambas se abordarán a continuación.

\section{Los efectos de la emergencia sanitaria en el plazo de la garantía legal}

Al suspenderse la exigibilidad de la obligación a causa de un evento que pueda calificarse como fuerza mayor -Coronavirus-, es que la prescripción no puede seguir corriendo como si nos encontrásemos en una situación de normalidad. No se trata entonces de un problema que involucre el dies a quo del plazo -ya principió-, por cuanto aun cuando el titular de un derecho tuviese pleno conocimiento de su existencia y disponibilidad, no puede ejercerlo por razones que escapan de su deseo y diligencia, se diferencia por lo tanto este supuesto, de la aplicación de un día de inicio de carácter subjetivo. La interrogante consiste en determinar "...qué pasa si por condiciones ajenas a su voluntad el acreedor no puede exigir su derecho, aún conociéndolo..." (Pizarro Wilson, 2020).

En otras latitudes, el propio Estado ha reconocido dicho principio. Así, en España, se ha decretado la interrupción del plazo contemplado para la devolución de un producto, durante todo el tiempo que dure el estado de alarma y sus eventuales prórrogas (Real Decreto-ley, 8/2020, art. 21). En Colombia en tanto, advertidos los efectos de la pandemia, se decretó la suspensión de los plazos de prescripción y ca-

\footnotetext{
2 En general existe consenso en orden a concebir a la triple opción como responsabilidad objetiva: Barrientos Camus (2014, p. 65); Corral Talciani (1999, p. 180); Corral Talciani (2011, p. 119); Fernández Fredes (1998, p. 119); Dte. o Qte.: Nelson Rodrigo Briones Moreno. Ddo. O Qdo.: Automotores Gildemeister S.A. Rep. Lorena León (2013.) En contra, algunos tribunales han exigido la acreditación de la imputabilidad para estimar que procede este remedio: Sernac - Valpuesta Aristegui Raúl - Almacenes Paris Com. S.A. - Bell Mardones Jo (2006)
} 
ducidad contemplados en cualquier norma sustantiva o procesal, para ejercer derechos, acciones, medios de control o presentación de demandas, sea de días meses o años, salvo los que se refieran a la responsabilidad penal (Decreto Legislativo, $\mathrm{N}^{\circ}$ 564, 2020, art. 1).

En nuestro país, la cuestión planteada no es resuelta por la Ley $\mathrm{N}^{\circ} 19.496$ (2019), ni en términos generales (procedencia y efectos de caso fortuito, fuerza mayor), ni a propósito de los regímenes de garantía. Tampoco, como se señaló, ha sido abordada por alguna de las normativas que han sido motivadas por la emergencia del COVID-19.

No obstante, el Servicio Nacional del Consumidor (Sernac), en el ejercicio de sus funciones, ha emitido una Circular interpretativa de la Ley $N^{\circ} 19.496$ (2019), en la cual propone una solución similar, esto es, la suspensión del plazo -lo califica de prescripción- de la garantía legal (Ley N 19.496, 2019, art. 21) mientras persista la imposibilidad de su ejercicio, la cual a su vez determina de acuerdo a un criterio formal, esto es, el inicio y fin del período del Estado de catástrofe por calamidad pública (Servicio Nacional de Consumidor, 2020, n. 3).

Si bien dicha directriz no tiene fuerza obligatoria de ley, es posible inferir una respuesta similar de las reglas y principios que sí se encuentran contenidas en nuestro ordenamiento jurídico.

\subsection{La tutela de la seguridad en el consumo}

El primer argumento que debe invocarse para defender la paralización del plazo contemplado para la garantía legal, es el resguardo de la seguridad en el consumo, en nuestro país consagrado en la Ley $N^{\circ} 19.496$ (2019, art. 3, d), cuya fórmula además abarca la tutela de la salud y del medio ambiente, aspectos todos que se encuentran fuertemente vinculados.

Dicha garantía buscar tutelar la integridad del consumidor (Zentner, 2017, p. 305). Tal es el propósito de los deberes de seguridad (Cabanillas Sánchez, 2000, p. 265; Díez-Picazo y Ponce de León, 2000, p. 18; Reyes López, 1998, p. 105). El deber de seguridad es equivalente al deber de protección (Cabanillas Sánchez, 2000, p. 267), y ya no la sola expectativa que se hubiere formado legítimamente respecto de las cualidades de una prestación ofrecida. De ello se derivan dos consecuencias relevantes para la temática en análisis.

La primera, dice relación con la posición jerárquica de la que goza y, por la cual, se encuentra ubicada en un estadio superior a la mera calidad del bien o servicio de que se trate (Fernández Fredes, 1997, p. 41). Por tal razón, y en atención a la no disponibilidad de los bienes jurídicos que en esta ocasión se encuentran comprometidos (salud, vida), tanto los deberes preventivos como los estándares de diligencia con los cuales deben satisfacerse se elevan en procedencia y contenido. Así, por 
ejemplo, lo ha señalado Contreras Chaimovic (2015, p. 284), a propósito de la determinación del ámbito de aplicación de la retirada obligatoria de productos: si bien en principio debe atenderse a la proporcionalidad, cualquier cálculo cede cuando lo que se encontrare en riesgo es un atentado grave a la integridad del ser humano; además, para Galdos (1997, p. 42) en caso de colisión de derechos, primará siempre la integridad del ser humano y el cuidado del medio ambiente. Lo propio ocurre en el caso planteado: la prevención de los graves daños derivados de un posible contagio, justifica con creces la no concurrencia del consumidor al lugar donde pueda solicitar el cumplimiento satisfactorio de la prestación.

Así también se ha estimado en la Resolución Exenta Nº340 del 09 de abril de 2020, ya aludida:

Siguiendo las descripciones normativas de la $L P D C$, es posible inferir que la protección de la persona del consumidor adquiere un valor esencial que prima frente a cualquier otro bien jurídico consignado en dicha Ley. Esta protección se proyecta en el cuidado de su vida, seguridad y salud, por lo que debe orientar la forma de cumplimiento de los contratos y demás deberes legales que disponen las leyes. (Servicio Nacional de Consumidor, 2020, n. 2)

Analizados los antecedentes que hasta ahora se conocen -y sobre todo, los que no se conocen- de los efectos del COVID-19, no cabe duda que la exposición de los consumidores a su contagio los pone en grave riesgo de contraer la enfermedad, sin que previamente se pueda anticipar que sólo presentarán síntomas leves. Por otra parte, el individuo afectado, aun cuando fuere asintomático, puede servir de vector para que el virus se propague a grupos de riesgo.

Cabe destacar, que esta reflexión no sólo se aplica a los acreedores de la triple opción, sino que también a los propios trabajadores y dependientes del proveedor, que pueden verse expuestos a sufrir e incrementar la pandemia, por concurrir al lugar de trabajo. En Chile, el Código del Trabajo también establece un deber de seguridad:

El empleador estará obligado a tomar todas las medidas necesarias para proteger eficazmente la vida y salud de los trabajadores, informando de los posibles riesgos y manteniendo las condiciones adecuadas de higiene y seguridad en las faenas, como también los implementos necesarios para prevenir accidentes y enfermedades profesionales. (Código del Trabajo, 2003, art, 184, inc. 1)

La segunda consecuencia, dice relación con la titularidad amplia que se le otorga al derecho a la seguridad en el consumo, derivada de su calificación de "básico". Ello implica que cualquier consumidor pueda reclamarlo, con independencia de si ha celebrado un contrato de consumo o no. Esta característica, resulta especialmente relevante en una economía fundamentada sobre la base de una sociedad de masas y en la cual, por lo tanto, un eventual riesgo no afectará sólo a un individuo 
determinado, sino que a la comunidad en general. Como se señaló, el eventual contagio de un solo consumidor que debiese presentarse en un local comercial para ejercer su derecho a la triple opción, puede conllevar una catástrofe de salud pública. Pensemos en los devastadores efectos a que dio lugar el tránsito libre de la mujer conocida como "Paciente 31" en Corea (Redacción, 2020).

En este contexto, y como ha señalado la literatura argentina, la necesaria reconstrucción de la economía que deberá tener lugar tras la pandemia, debe realizarse con la mirada puesta en los consumidores (Krieger, 2020), quienes son los protagonistas de la sociedad de consumo.

\subsection{Reglas y principios de los plazos extintivos}

Los principios y reglas propios de los plazos extintivos, igualmente pueden ser invocados para defender la suspensión del plazo de la garantía legal.

\subsubsection{La función sancionatoria de la prescripción}

Uno de los fundamentos principales de la prescripción, radica en la sanción del acreedor negligente en el ejercicio de los derechos de los que es titular ${ }^{3}$. Se persigue entonces, mediante la limitación temporal de la eficacia de una determinada facultad, el reproche de aquel individuo que no ha sido diligente en la satisfacción de su crédito.

Ahora bien, en el supuesto modelo enunciado, el no ejercicio de la triple opción no puede ser reprendido, desde que la ausencia de la solicitud de alguna de las prestaciones que conforman la garantía legal no se deriva de una desidia del comprador -él quiere realizarla-, sino que a una imposibilidad fáctica en su verificación.

Por otra parte, y aunque podemos debatir acerca de la naturaleza del plazo de la garantía legal - ¿caducidad o prescripción? (Sobre la calificación de la garantía legal ver, Isler Soto, 2017, pp. 93-104) -, resulta del todo invocable el principio que se imprime en el aforismo contra non valentem, agere non currit praescriptio, por el cual no es posible concebir que un término extintivo pueda seguir corriendo como si nos encontrásemos en condiciones de "normalidad", siendo que el tránsito de las personas se encuentra restringido o incluso prohibido.

Aunque Pizarro Wilson no llega a defender el efecto indicado, sí acusa la urgencia de que el mismo principio sea objeto de una nueva reflexión a la luz de la contingencia:

\footnotetext{
${ }^{3}$ Abeliuk Manasevich (2008, p. 1189); Barros Bourie (2007, p. 924); Delvincourt (1808, p. 356); Delvincourt (1813, p. 79); García Goyena (1852, p. 301); Lanata Fuenzalida (2010, p. 244); Revilla González (2006, p. 66); Stoffel-Munck(2010, p. 384); Cooperativa Agrícola Río Bueno con Indap. (2018)
}

Rev. derecho (Coquimbo, En línea) 2020, 27: 4107 
Parece necesario avanzar en el uso de la regla non valente magere non praescriptio por el momento, como un atenuante de la rigidez que presenta el precepto previsto en el artículo 2514 del Código Civil, cuyo tenor objetivo y rígido impide adaptarse en situaciones en que el acreedor pueda verse impedido o dificultado en forma severa, sin culpa de su parte, para ejercer los derechos y reclamar su crédito produciendo el efecto de interrupción de la prescripción. La forma estrecha en que se han tratado las suspensiones de la prescripción merece una revisión. (Pizarro Wilson, 2020)

El Sernac, ha invocado el mismo argumento para defender la suspensión de la garantía legal:

...una interpretación armónica de las normas de la LPDC y sus principios, permite sostener que, debido a que los consumidores acreedores no pueden ejercer sus derechos que emanan de las garantías y derechos de retracto legal, pues se encuentran impedidos; debe suspenderse el plazo de prescripción de los derechos establecidos en la LPDC... (Servicio Nacional de Consumidor, 2020, n. 1)

Dicha consideración es correcta, toda vez que, como se dijo, la inactividad del consumidor obedece únicamente a una imposibilidad fáctica o incluso ética, de ejercer su derecho. En efecto, ya salir al espacio público constituye un riesgo para sí y el resto de la comunidad.

\subsubsection{A lo imposible nadie está obligado}

Fuertemente vinculado al principio anteriormente analizado, se encuentra el conocido aforismo "a lo imposible nadie está obligado". En concreto, como se ha venido reiterando, sostener que el plazo de tres meses contemplado la Ley $N^{\circ} 19.496$ (2019, arts. 20 y 21) continúa corriendo, pese a que no se verifican las condiciones para que el consumidor pueda optar por una de las opciones que se le confieren, implicaría poner de cargo de él la imposibilidad fáctica y jurídica de activar el remedio. Incluso ello, lo situaría en la incómoda posición de decidir entre obtener el cumplimiento íntegro de la prestación y el resguardo de su propia integridad, cálculo que, como se dijo, no resulta procedente en atención a que la segunda siempre deberá privilegiarse.

Así también lo ha comprendido el Sernac:

...la lógica sugiere que los estados de excepción constitucional y decretos de cuarentenas obligatorias que se han decretado en algunas zonas del país, producen efectos en los contratos de consumo celebrados con proveedores, toda vez que los consumidores tienen severas restricciones a su libertad de desplazamiento y movilización y que, además, los proveedores están asumiendo modalidades de teletrabajo o cierre de locales o puntos de venta, $y$ 
por ende, del deber legal de atención de postventa. (Servicio Nacional del Consumidor, 2020, n. 3)

Ahora bien, el campo de procedencia de la extensión del tiempo al que se ha aludido, no sólo debe corresponder a las comunas en las cuales por un acto de autoridad se hubiere decretado una cuarentena obligatoria, sino que a todo el país. Lo anterior, en atención a que la ausencia de una orden estatal en tal sentido, no significa que el confinamiento social no sea necesario -su urgencia la ha explicitado tanto la comunidad científica como el propio gobierno-, sino que únicamente que se ha considerado que por razones de orden público constituiría un mal menor frente a problemáticas que merecerían una mayor atención, al menos por un tiempo (pensemos en la violencia intrafamiliar, ciertos trabajos, condiciones de vida bajo la línea de la pobreza, etc.). La imposibilidad en el ejercicio del derecho en ese sentido, es amplia.

\subsubsection{La exigencia de la utilidad del plazo}

De acuerdo a una adecuada técnica normativa, los plazos que el ordenamiento jurídico confiere al titular de un derecho para ejercerlo adecuadamente, deben ser útiles (Ripert y Boulanger, 1965, p. 617), lo que ocurrirá en la medida de que su regulación permita otorgar una efectiva eficacia a la prerrogativa de que se trate. Así también agrega Finkenauer (2006, p. 368) que el acreedor debería tener una oportunidad justa para la obtención de su pretensión.

Tal principio, además de fundamentar el inicio subjetivo de los términos breves, trasunta detrás de la justificación de las causales de suspensión de la prescripción. Así, a esta última, también conocida como dormiction, se la concibe como un beneficio que el legislador otorga a ciertas personas, que consiste en hacer dormitar el plazo -no se pierde el que ya ha corrido-, mientras dure un obstáculo que impide su curso (Correa Gómez,1929, p. 43). Escalona Riveros (1997) lo define como:

...un beneficio que la ley contempla a favor de ciertas personas en virtud del cual cesa el curso del plazo de prescripción dejando subsistente todo el lapso anteriormente transcurrido, si alguno hubo y admitiendo que éste se reanude hasta su posible entero, una vez desaparecidas o enervadas las causas que originaron el intervalo no utilizable. (pp. 230 y 231)

En este contexto, de considerarse que el término de la Ley $\mathrm{N}^{\circ} 19.496$ (2019, art. 20) continúa corriendo durante un período en el cual, el comprador no tiene posibilidad de ejercer su derecho, implicaría desde luego, que el tiempo que se le ha conferido para realizarlo no podría ser calificado de útil. Ello además, haría tornar la garantía legal en una prerrogativa meramente romántica e ideal, de la cual su titular podría no obtener provecho alguno por causas que no le son imputables. 


\subsubsection{La ponderación de la justicia y la certeza jurídica en el contexto del con-} trato

La regulación del tiempo de vigencia de los derechos, se obtiene mediante la conjugación de imperativos de justicia y de certeza. Así, por ejemplo, los términos breves suelen ir asociados a momentos de inicio subjetivos, y los objetivos suelen proceder en los más extensos (Isler Soto, 2017, p. 195; Lamarca i Marquès, 2002, p. 4). En ese sentido, la brevedad de la duración de la garantía legal, insinuaría también que no resultaría justo permitir que continúe corriendo cuando no fuere posible que el acreedor salga de la inactividad.

Así mismo, y en invocación de los estándares que conforman el equilibrio contractual, cada convención, sus efectos y estatuto, deben ponderarse en su propio contexto. Como explica Brantt Zumarán (2009):

El contrato no puede ser entendido en su esencia si se le examina sólo como noción jurídica, sino que debe ser apreciado en conexión con la realidad en que se inserta y dentro de la cual desempeña una función concreta: ser una herramienta para la satisfacción de intereses patrimoniales concretos de las partes, de modo que en definitiva constituye la formalización jurídica de una operación económica. (p. 65)

A mayor abundamiento, la suspensión de la exigibilidad de la obligación -y su correspondiente plazo de prescripción-, debe examinarse de acuerdo a la naturaleza y circunstancias de la obligación, a la causa del contrato, la buena fe y el contexto económico y negocial que enmarcan la imposibilidad (Arias, 2020).

De acuerdo a lo anterior, las diversas asimetrías que distancian a un proveedor y a un consumidor -informativa, poder de negociación-, deben ser tomadas entonces en consideración al momento de determinar la procedencia y alcance de las obligaciones que se derivan de una relación de consumo. En este sentido, dicho examen impediría también que no se resguarde un derecho del consumidor, mientras duren las circunstancias que le impiden ejercerlo.

\subsubsection{La excepcionalidad de la extinción del derecho}

Resulta pertinente recordar, que los plazos extintivos no constituyen la regla general, sino que se trata de elementos excepcionales, que pueden ser introducidas por el legislador o las partes a un vínculo jurídico. Las disposiciones que las consagran, por lo tanto, deben recibir una exégesis restrictiva, directriz que unida al principio pro consumidor, nos conducen a la conclusión de que frente a la incertidumbre acerca de la vigencia o no del derecho, debemos decantarnos por una respuesta positiva.

Así, a propósito de la prescripción extintiva, Elorriaga de Bonis (2011, pp. 5051) ha explicado que en caso de duda acerca del sentido y alcance de las normas que 
la regulan, ha de privilegiarse aquella solución que favorezca la reparación, y no la imposibilidad física o material del resarcimiento de la víctima - Se refiere a la determinación del dies a quo del plazo de prescripción (Elorriaga de Bonis, 2011b, p. 282), en invocación de un fundamento similar, Cordón Moreno (2008, p. 85) sostiene que la aplicación no rigorista (restrictiva) de la prescripción, implica que frente a la indeterminación del dies a quo no debe en principio resolverse en contra de la persona titular del derecho, sino que en perjuicio de quien pretende la extinción -. Además agrega "...su declaración es una actuación de última medida, que el sentenciador sólo debe asumir cuando no es posible sustentar ningún criterio favorable a la subsistencia del derecho" (Elorriaga de Bonis, 2011b, p. 289).

Si aplicamos el mismo criterio a la procedencia y efectos de la garantía legal, es posible deducir que, de no existir claridad en torno a la posibilidad de que el plazo al cual se encuentra sometida pueda continuar corriendo, aunque se enmarque dentro de circunstancias extraordinarias que impidan su ejercicio, o bien es posible concebir una alteración de la regla por la cual se suspenda, se debe privilegiar esta segunda opción.

\subsection{Plazo para ejercer el derecho y plazo de advertencia del vicio}

Si la justicia impide que el plazo de la garantía legal continúe corriendo mientras exista una imposibilidad de su ejercicio, la disciplina de este remedio sugiere, al mismo tiempo, que lo que realmente se despliegue en el tiempo sea el día en que culmina la oportunidad para ejercerla. El vicio del producto que permite activar la triple opción, por el contrario, debe al menos aparecer dentro del término ordinario.

Otros sistemas han reconocido lo anterior bajo la figura de la "posposición" (European Union, 2002, cap. 14, sec. 3; Bürgerliches Gesetzbuch, 1896, §§ 210 y 211), que consiste en "... diferir el momento del vencimiento del plazo. El tiempo aquí sigue su curso, pero el plazo de prescripción solo se completa después de un período adicional" (Domínguez Luelmo y Álvarez Álvarez, 2009, p. 17) -en contra, se ha sostenido que, no obstante su denominación, igualmente son casos de suspensión (Peña López, 2011, p. 10)- . Bajo este supuesto, entonces, el plazo no se detiene, pero su último día se prorroga hasta un evento futuro (por ejemplo, en el supuesto planteado, el control de la pandemia).

En el caso en estudio, por lo tanto, lo que puede quedar pendiente para después de la finalización de la emergencia sanitaria, es la realización del reclamo por parte del consumidor afectado, debiendo la anomalía que de origen a la garantía legal, presentarse de acuerdo a la regla general. Lo anterior, por cuanto la ocurrencia de este segundo evento, a diferencia de la reclamación, no se ve imposibilitada por la contingencia. 
Todo lo cual se entiende, sin perjuicio de la acción indemnizatoria que tenga por objeto resarcir eventuales daños provocados a los consumidores, la cual se encuentra sometida a sus propios plazos de prescripción.

\section{Algunos deberes adicionales}

Existe también un segundo efecto a que puede dar lugar la ocurrencia de la fuerza mayor y que dice relación con la aparición eventual de nuevos deberes para con el acreedor, si se cumplen ciertos presupuestos.

Brantt Zumarán (2011, p. 77), así sostiene que aun de configurarse un supuesto de caso fortuito, y con esto se suspendiese la exigibilidad de la obligación, ello no faculta al deudor a permanecer en una situación pasiva, sino que igualmente debe desplegar la actividad que corresponda según la diligencia que el ordenamiento jurídico le exija, para superar el obstáculo que impida la total satisfacción del crédito. Por tal razón, agrega, que la diligencia promotora pone al deudor en la necesidad de actuar frente a eventos -incluso imprevistos- posteriores a la celebración del contrato y que puedan afectar el cumplimiento de su obligación, adoptando las medidas adecuadas para impedir que ello ocurra, hasta que se produzca el cumplimiento propiamente tal, y con independencia de la naturaleza de la prestación principal (Brantt Zumarán, 2011, p. 58).

Ahora bien, en el supuesto planteado, el primer imperativo que surge para el proveedor que ha cerrado sus locales comerciales, es contemplar los medios de información adecuados y suficientes para satisfacer el derecho básico a una información veraz y oportuna (Ley N 19.496, 2019, art. 3, b). En efecto, el reconocimiento de tal garantía implica que aun cuando no se pueda ejercer la garantía legal, el sujeto pasivo debe adoptar una conducta positiva en orden a poner al consumidor en antecedentes acerca de la forma y oportunidad en la cual podrá ejercer la triple opción (Servicio Nacional del Consumidor, 2020). Lo anterior, tanto si es requerido por el acreedor -canales de atención al público- como de iniciativa propia, lo que además le otorgará la tranquilidad de que su crédito será resguardado.

El Servicio Nacional del Consumidor (2020), por su parte, ha agregado que este mismo imperativo debe cumplirse con la Institucionalidad, de tal manera que el proveedor se encuentra también obligado a informarlo acerca de las medidas que ha estado implementando. 


\section{Conclusiones}

Las reflexiones anteriores, así como el orden de protección en el cual se inserta la relación de consumo, permiten arribar a la conclusión de que el plazo de tres meses contemplado para el ejercicio de la garantía legal (Ley No 19.496, 2019, art. 21 inc. 2) no puede entenderse extinguido, si su término se enmarca dentro del período que dure la emergencia sanitaria.

Ello se obtiene a partir de que la ocurrencia de la pandemia derivada del COVID-19, si bien constituye un caso fortuito, no hace fenecer derechos cuya exigibilidad no se encuentra sometida a una imposibilidad absoluta, sino que sólo temporal.

No obstante, igualmente dará lugar a dos importantes consecuencias jurídicas: la suspensión del plazo establecido en la Ley № 19.496 (2019) para solicitar algunas de las prestaciones que integran la triple opción y el surgimiento de nuevos deberes. La primera de ellas además encuentra sustento en el resguardo de la seguridad en el consumo, así como en los principios y reglas aplicables a los plazos extintivos.

\section{Agradecimientos}

El presente artículo forma parte del proyecto FONDECYT de Iniciación № 11190230: "Los medios de tutela del consumidor ante el producto defectuoso, en la Ley 19.496" del que la autora es investigadora responsable

\section{Referencias Bibliográficas}

Abeliuk Manasevich, R. (2008). Las obligaciones (5a ed., Vol. 2). Santiago: Jurídica de Chile.

Arias, M. P. (2020). La tutela del consumidor en tiempos de pandemia. Revista de derecho del consumidor, (8), Art ID. IJ-CMXV-217. Recuperado de https://bit.ly/2YDdEze

Barrientos Camus, F. M. (2014). La articulación de remedios en el sistema de la responsabilidad civil del consumo. Revista de derecho (Valparaíso), (42), 57-82. doi: $10.4067 /$ s0718-68512014000100002

Barros Bourie, E. (2007). Tratado de responsabilidad extracontractual. Santiago: Jurídica de Chile.

Benítez, N. (2013). Responsabilidad postcontractual y deberes secundarios de conducta. Revista jurídica de daños, (7), Art ID. IJ-LXIX-876. Recuperado de https://bit.ly/3b6PShx 
Brantt Zumarán, M. G. (2009). La exigencia de exterioridad en el caso fortuito: su construcción a partir de la distribución de los riesgos del contrato. Revista de derecho (Valparaíso), (33), 39-102. doi: 10.4067/s0718-68512009000200001

Brantt Zumarán, M. G. (2011). El caso fortuito: concepto y función como límite de la responsabilidad contractual. Cuadernos de análisis jurídico, (7), 47-82. Recuperado de https://bit.ly/2W832X6

Bürgerliches Gesetzbuch. Reichs Gesetzblatt, Berlín, Alemania, 24 de agosto de 1896. Recuperado de https://bit.ly/2Lbi4oM

Cabanillas Sánchez, A. (2000). Los deberes de protección del deudor en el Derecho Civil, en el Mercantil y en el Laboral. Madrid: Civitas.

Código Civil. Diario Oficial de la República de Chile, Santiago, Chile, 30 de mayo de 2000. Recuperado de http://bcn.cl/1 uqm8

Código del Trabajo. Diario Oficial de la República de Chile, Santiago, Chile, 16 de enero de 2003. Recuperado de http://bcn.cl/1uvqw

Contreras Chaimovich, L. (2015). La responsabilidad penal del fabricante por la infracción de sus deberes de vigilancia, advertencia y retirada. Política criminal, 10(19), 266-296. doi: 10.4067/s0718-33992015000100009

Cooperativa Agrícola Río Bueno con Indap., Rol № 37180.2017 (Corte Suprema 15 de marzo de 2018). Recuperado de https://bit.ly/35JQicK

Cordón Moreno, F. (2008). Las excepciones de prescripción y caducidad (Leyes 26 y 27 del Fuero Nuevo). Revista jurídica de Navarra, (45), 77-101. Recuperado de https://bit.ly/3dfOudK

Corral Talciani, H. (1999). Ley de protección al consumidor y responsabilidad civil por productos y servicios defectuosos. Cuadernos de extensión jurídica, (3), 163-211. Recuperado de https://bit.ly/2YEU7y3

Corral Talciani, H. (2011). Responsabilidad por productos defectuosos. Santiago: Abeledo Perrot.

Corral Talciani, H. (2020). Caso fortuito y suspensión de pago de remuneraciones [Blog]. Recuperado de https://bit.ly/3dIGQPf

Corral Talciani, H. (9 de abril de 2020). Cambios a la prescripción civil por la catástrofe del covid-19. El Mercurio - Legal. Recuperado de https://bit.ly/2YCiSLx

Correa Gómez, A. (1929). Suspensión e interrupción de la prescripción extintiva (Tesis licenciado en ciencias jurídicas y sociales). Universidad de Chile, Facultad de leyes, ciencias políticas y teología. 
De la Maza Gazmuri, Í. (3 de abril de 2020). El caso fortuito en los tiempos del coronavirus. El Mercurio - Legal. Recuperado de https://bit.ly/3b2KLyQ

De la Maza Gazmuri, Í. y Vidal Olivares, Á. (11 de Abril de 2020). Algunas ideas para la discusión del caso fortuito. Idealex.press. Recuperado de https://bit.ly/2YFMmrM

Decreto Legislativo $N^{\circ}$ 564. Por el cual se adoptan medidas para la garantía de los derechos de los usuarios del sistema de justicia, en el marco del Estado de Emergencia Económica, Social y Ecológica. Diario Oficial de Colombia, Bogotá, Colombia, 15 de abril de 2020. Recuperado de https://bit.ly/3duwoVL

Delvincourt, M. (1808). Institutes de Droit Civil Français conformément aux dispositions du Code Napoléon (Vol. 2). Paris: P. Gueffier. Recuperado de https://bit.ly/2L14IAY

Delvincourt, M. (1813). Cours de Code Napoléon (Vol. 2). Paris: P. Gueffier. Recuperado de https://bit.ly/2L5EOIm

Díez-Picazo y Ponce de León, L. (2000). Prólogo. En A. Cabanillas Sánchez, Los deberes de protección del deudor en el Derecho Civil, en el Mercantil y en el Laboral (pp. 17-24). Madrid: Civitas.

Domínguez Luelmo, A. y Álvarez Álvarez, H. (2009). La prescripción en los PECL y en el DCFR, InDret, (3). Recuperado de https://bit.ly/2zVe09R

Dte. o Qte.: Nelson Rodrigo Briones Moreno. Ddo. O Qdo.: Automotores Gildemeister S.A. Rep. Lorena León, Rol N²06-2013 (Corte de Apelaciones de Concepción 5 de noviembre de 2013). Recuperado de https://bit.ly/2YIBiKo

Elorriaga de Bonis, F. (2011). Del día de inicio del plazo de prescripción de una acción indemnizatoria cuando el perjuicio se ha manifestado con posterioridad al hecho que lo origina. Cuadernos de extensión jurídica, (21), 39-61. Recuperado de https://bit.ly/2L5hucs

Elorriaga de Bonis, F. (2011b). El día de inicio de plazo de prescripción de una acción indemnizatoria cuando el perjuicio se ha manifestado con posterioridad al hecho que lo origina. En H. Corral Talciani, A. Guzmán Brito, C. Pizarro Wilson, M. S. Rodríguez Pinto, S. Turner Saelzer, J. A. Varas Braun y Departamento de Derecho Privado Universidad de Concepción (Coord.), Estudios de derecho civil. (Vol.4, pp. 271-289). Santiago: Thomson Reuters.

Escalona Riveros, F. (1997). La prescripción extintiva civil. Santiago: Conosur.

European Union. (2002). The principles of european contract law 2002 (Parts I, II, and III). Recuperado de https://bit.ly/2yBRiu0

Fernández Fredes, F. (1997). La protección jurídica de la calidad. Cuadernos de análisis jurídico, (33), 35-46. 
Fernández Fredes, F. (1998). Nueva Ley del consumidor: innovaciones y limitaciones. Perspectivas en política, economía y gestión, 1(2), 107-126. Recuperado de https://bit.ly/3fqezcg

Finkenauer, T. (2006). El nuevo derecho de prescripción. En H. Ehmann y H. Sutschet (Eds.), C. López Díaz y U. Salach de Sánchez (Trads.), La reforma del BGB: modernización del derecho alemán de obligaciones (pp. 367-394). Bogotá: Universidad del Externado de Colombia.

Galdos, J. M. (1997). El principio favor debilis en materia contractual. En G.A. Stiglitz (Ed.), Derecho del Consumidor (Vol. 10, pp. 37-47). Rosario: Juris.

García Goyena, F. (1852) Concordancias, motivos y comentarios del Código Civil Español (Vol. 4). Madrid: Imprenta de la Sociedad Tipográfico-Editorial. Recuperado de https://bit.ly/3do02Mm

Isler Soto, E. (2017). Prescripción extintiva en el Derecho del Consumo. Santiago: Rubicón.

Isler Soto, E. (2019). Acerca de la responsabilidad civil postcontractual en el derecho del consumidor chileno. Ius et praxis, 25(1), 335-382. doi: 10.4067/s071800122019000100335

Krieger, W. F. (2020). Las relaciones de consumo después de la pandemia: herramientas del CCyCN que aportan soluciones al problema. Revista de derecho del consumidor, (8), Art. ID. IJ-CMXV-240. Recuperado de https://bit.ly/2Wwzulb

Lanata Fuenzalida, G. (2010). Prescripción y caducidad en el Derecho del Trabajo. Revista de derecho (Concepción. En línea), 79(227-228), 239- 272. Recuperado de https://bit.ly/2SEw7Hx

Ley $N^{\circ} 19.496$. Establece normas sobre protección de los derechos de los consumidores. Diario Oficial, Santiago, Chile, 07 de marzo de 2019. Recuperado de http://bcn.cl/1uvuj

Ley $\mathrm{N}^{\circ} 21.226$. Establece un régimen jurídico de excepción para los procesos judiciales, en las audiencias y actuaciones judiciales, y para los plazos y ejercicio de las acciones que indica, por el impacto de la enfermedad Covid-19 en Chile. Diario Oficial de la República de Chile, Santiago, Chile, 02 de abril de 2020. Recuperado de http://bcn.cl/2djow

Ley N ${ }^{\circ}$ 26.994. Código Civil y Comercial Nacional. Boletín Oficial de la República Argentina, Buenos Aires, Argentina, 08 de octubre de 1994. Recuperado de https://bit.ly/2yCl363 
Momberg Uribe, R. (6 de abril 2020). La obligación del arrendatario durante la pandemia por coronavirus. Recuperado de https://bit.ly/2YHfdMC

Peña López, F. (2011). El dies a quo y el plazo de prescripción de las acciones de responsabilidad por daños en el CC: criterios procedentes de algunos textos europeos de soft law y del Derecho estadounidense que podrían servir para su reforma e interpretación. InDret, (4). Recuperado de https://bit.ly/2WMsbpN

Pizarro Wilson, C. (24 de marzo de 2020). La peste que imposibilita actuar. ¿Suspender la prescripción?. El Mercurio - Legal. Recuperado de https://bit.ly/2Wx6D0b

Pizarro Wilson, C. (26 de marzo de 2020b). Epidemia, imprevisión y fuerza mayor. Idealex.press. Recuperado de https://bit.ly/3b7v4q5

Real Decreto-ley 8/2020. De medidas urgentes extraordinarias para hacer frente al impacto económico y social del COVID-19. Boletín Oficial del Estado, Madrid, España, 17 de marzo de 2020. Recuperado de https://bit.ly/3fvKOBF

Redacción. (21 de Febrero de 2020). 'Paciente 31': la mujer con coronavirus seguidora de una secta que pone en jaque a Corea del Sur. La Voz de Galicia. Recuperado de https://bit.ly/2WctWgH

Reyes López, M. J. (1998). La responsabilidad civil del fabricante por productos defectuosos: estudios de la Ley de 6 de julio de 1994, En A. B. Campuzano Laguillo (Coord.) y F. J. Orduña Moreno (Dir.), Contratación y consumo. Valencia: Tirant lo Blanch.

Revilla González, J. A. (2006). Los métodos alternativos de resolución de conflictos en materia de consumo: las relaciones transfronterizas. Estudios sobre consumo, (79), 5973. Recuperado de https://bit.ly/2L5rL8j

Ripert, G. y Boulanger, J. (1965). Tratado de Derecho Civil: según el Tratado de Planiol. (D. García Diareaux, Trad.) (Vol. 5). Buenos Aires: La Ley.

San Martín Neira, L. (2019). Desastres naturales y responsabilidad civil. Identificación de los desafíos que presenta esta categoría de hechos dañinos. Revista de derecho (Valdivia), 32(2), 123-142. doi: 10.4067/s0718-09502019000200123

San Martín Neira, L. (18 de marzo de 2020), 27F, 180 y Covid-19: derecho de desastres y caso fortuito. El Mercurio - Legal. Recuperado de https://bit.ly/3b7GpXb

Sernac - Valpuesta Aristegui Raúl - Almacenes Paris Com. S.A. - Bell Mardones Jo, Rol № 72622-2006 (Corte de Apelaciones de Santiago 27 de septiembre de 2006). Recuperado de https://bit.ly/3cdBPYT

Servicio Nacional de Consumidor. (2020). Resolución Exenta $N^{\circ}$ 0340, circular interpretativa sobre suspensión de plazos de las garantías legales, voluntarias y de satis- 
La incidencia del Covid-19 en el ejercicio de la garantía legal

facción durante la crisis sanitaria derivada de Covid-19, Santiago: Ministerio de Economía, Fomento y Turismo. Recuperado de https://bit.ly/3fqZGpT

Stoffel-Munck, P. (2010). La prescription extinctive: le role de la volonté et du comportement des parties. En P. Jourdain y P. Wéry (Eds.), La prescription extinctive - Etudes de Droit Comparé (pp. 384-402). Bruxelles: Bruylant.

Zentner, D. H. (2017). La responsabilidad por productos defectuosos en el Derecho Argentino. En J. C. Villalba Cuéllar y A. Alarcón Peña (Dirs.), Escritos de derecho privado contemporáneo: contratos, responsabilidad y mercado en el siglo XXI (pp. 299-323). Bogotá: Ibáñez.

\section{Para citar este artículo bajo Norma APA 6a ed.}

Isler Soto, E. (2020). La incidencia del Covid-19 en el ejercicio de la garantía legal. Revista de derecho (Coquimbo. En línea), 27, e4107, https://doi.org/10.22199/issn.0718-9753-20200005 